\title{
Statins, news, and nuance
}

\author{
(a) (1) $\Theta$ OPEN ACCESS \\ Journalism that exposes the public to ongoing controversies in science should be nurtured
}

Gary Schwitzer journalist and adjunct associate professor

University of Minnesota School of Public Health, 2221 University Avenue, SE, 350 University Office Plaza, Minneapolis MN 55414-3078, USA

Did news coverage of questions about the risk:benefit balance of statins influence their use in the United Kingdom? In a linked paper, Matthews and colleagues (doi:10.1136/bmj.i3283) assert that it did, describing "impact," "the effect of negative media coverage," and "a transient rise in the proportion of people who stopped taking statins."1 They assumed causality but did not prove it, despite the causal language used.

The news in question was not all negative. Stories swung between extremes. One newspaper headline claimed that "statins do not have major side effects" just days after another newspaper headlined "millions face terrible side effects as [statin] prescription escalates." Those two stories might have had very different effects on current or potential statin users.

Two stories are a slim sample on which to base conclusions, but that is all the authors cited, after describing "widespread media coverage" over a six month period that was both "intense" and "negative." In one story, less than $20 \%$ of the text discusses potential harms. ${ }^{2}$ The headline of the other story was "Doctors' fears over statins may cost lives, says top medical researcher." We should not rush to judge the media's role in this episode. The authors provide no patient survey data to support the belief that people stopped because of news reports.

It is noteworthy that another linked paper about discontinued use of statins (doi:10.1136/bmj.i3305) included this limitation: "Because of the lack of data on reasons for discontinuations, this study cannot directly address why patients discontinue statins." ${ }^{4}$ Vinogradova and colleagues concluded, "Although a large proportion of statin users discontinue, many of them restart."

But what if news coverage did have an effect, by alerting people to the debate and uncertainty that still exist about the extent of potential benefits and harms of statin use? Is that such a bad thing? As Montori and others have said, "Informed patients may choose not to follow a guideline that does not incorporate their preferences." 5

What do we know about patients' preferences in this case? Perhaps news stories inspired patients to question trade-offs in ways they never did when they started taking statins because they had not been fully informed. We know nothing about the quality of the clinical decision making encounters before the start of treatment. We know nothing about why these patients stopped. Matthews and colleagues acknowledge that they did not engage patients in the development of the study protocol. It might have helped if they had done so. A survey in the United States found that patients perceive that physicians tend to emphasise the advantages more than the disadvantages in 10 common decisions about care. ${ }^{6}$ Furthermore, patients in that survey reported that treatment of raised cholesterol concentration was one of the decisions for which they were least likely to be asked for input.

So we do not know whether the news coverage on statins had any causal effects on people taking statins, what other factors could have influenced patients' decisions to stop, and why initiation of new use did not decline after this same "negative" news coverage. Hanging over all of this are questions about what manufacturers' data that have not been made public or what better studies of statins in routine use might further reveal about harms. Statin intolerance is not a myth. ${ }^{7}$

For 10 years I have published HealthNewsReview.org, a US based project that systematically reviews media messages that make claims about healthcare interventions. ${ }^{8}$ Our data on several thousand stories show that most emphasize or exaggerate potential benefits while minimizing or ignoring potential harms. ${ }^{9}$ We rarely see journalism about overdiagnosis, overtreatment, or shared decision making. Few stories clearly communicate the trade-offs involved in medical decisions. Far more stories fawningly promote more use of more interventions, evidence be damned. Journalism that exposes the public to ongoing controversies in science should be nurtured, not branded as negative.

Matthews and colleagues projected excess cardiovascular events as a result of discontinued statin use. ${ }^{1}$ They did not explore the possibility of reduced reports of muscle pain, rhabdomyolysis, liver damage, diabetes, or cognitive side effects.

The debate over the harms and benefits of statins is not over. Journals, journalists, clinicians, and researchers could help people to grasp the uncertainty that still exists and to attack it 
by asking more questions. But they must avoid suggesting absolute certainty exists where it does not.

If news stories generate new questions from patients, or more complete conversations between patients and clinicians including better discussions on trade-offs, personal preferences, and values, that is an outcome to embrace. In the end, I suggest that this episode is far less about journalism than about how science and medicine deal with uncertainty.

Competing interests: I have read and understood the BMJ policy on declaration of interests and have no interests to declare.

Provenance and peer review: Commissioned; not peer reviewed.

1 Matthews A, Herrett E, Gasparrini A, et al. Impact of statin related media coverage on use of statins: interrupted time series analysis with UK primary care data. BMJ 2016;353:i3283.

2 Statins do not have major side effects, claims study: Research finds users less likely to suffer maladies than control group. Daily Mail 2014 March 12. http://www.dailymail.co.uk/ health/article-2579739/Statins-NOT-major-effects-claims-study-Research-finds-userslikely-suffer-maladies-control-group.htm
3 Doctors' fears over statins may cost lives, says top medical researcher. The Guardian 2014 March 21. http//www theguardian.com/society/2014/mar/21/-sp-doctors-fears-overstatins-may-cost-lives-says-top-medical-researcher

4 Vinogradova Y, Coupland C, Brindle P, Hippisley-Cox J. Discontinuation and restarting in patients on statin threatment: cohort study using a primary care database. BMJ 2016;353:i3305.

5 Montori VM, Brito JP, Murad MH. The optimal practice of evidence-based medicine: incorporating patient preferences in practice guidelines. JAMA 2013;310:2503-4. doi:10. 1001/jama.2013.281422 pmid:24165826.

6 Fowler FJ Jr, , Gerstein BS, Barry MJ. How patient centered are medical decisions?: Results of a national survey. JAMA Intern Med 2013;173:1215-21. doi:10.1001/ jamainternmed.2013.6172 pmid:23712194.

7 Statin intolerance: not a myth. American College of Cardiology, 2015. http://www.acc.org/ latest-in-cardiology/articles/2015/08/11/09/16/statin-intolerance-not-a-myth

8 Schwitzer G. A guide to reading health care news stories. JAMA Intern Med 2014;174:1183-6. doi:10.1001/jamainternmed.2014.1359 pmid:24796314.

9 Schwitzer G. Trying to Drink from a Fire Hose: Too Much of the Wrong Kind of Health Care News. Trends Pharmacol Sci 2015;36:623-7. doi:10.1016/j.tips.2015.08.005 pmid: 26435207.

Published by the BMJ Publishing Group Limited. For permission to use (where not already granted under a licence) please go to http://group.bmj.com/group/rights-licensing/ permissions

This is an Open Access article distributed in accordance with the Creative Commons Attribution Non Commercial (CC BY-NC 3.0) license, which permits others to distribute, remix, adapt, build upon this work non-commercially, and license their derivative works on different terms, provided the original work is properly cited and the use is non-commercial. See: http://creativecommons.org/licenses/by-nc/3.0/. 